\title{
Practice parameter: Temporal lobe and localized neocortical resections for epilepsy
}

\section{Report of the Quality Standards Subcommittee of the American Academy of Neurology, in Association with the American Epilepsy Society and the American Association of Neurological Surgeons}

\author{
J. Engel, Jr., MD, PhD; S. Wiebe, MD; J. French, MD; M. Sperling, MD; P. Williamson, MD; \\ D. Spencer, MD; R. Gumnit, MD; C. Zahn, MD; E. Westbrook, MD; and B. Enos, MD, PhD
}

\begin{abstract}
Objectives/Methods: To examine evidence for effectiveness of anteromesial temporal lobe and localized neocortical resections for disabling complex partial seizures by systematic review and analysis of the literature since 1990 . Results: One intention-to-treat Class I randomized, controlled trial of surgery for mesial temporal lobe epilepsy found that $58 \%$ of patients randomized to be evaluated for surgical therapy ( $64 \%$ of those who received surgery) were free of disabling seizures and 10 to $15 \%$ were unimproved at the end of 1 year, compared with $8 \%$ free of disabling seizures in the group randomized to continued medical therapy. There was a significant improvement in quantitative quality-of-life scores and a trend toward better social function at the end of 1 year for patients in the surgical group, no surgical mortality, and infrequent morbidity. Twenty-four Class IV series of temporal lobe resections yielded essentially identical results. There are similar Class IV results for localized neocortical resections; no Class I or II studies are available. Conclusions: A single Class I study and 24 Class IV studies indicate that the benefits of anteromesial temporal lobe resection for disabling complex partial seizures is greater than continued treatment with antiepileptic drugs, and the risks are at least comparable. For patients who are compromised by such seizures, referral to an epilepsy surgery center should be strongly considered. Further studies are needed to determine if neocortical seizures benefit from surgery, and whether early surgical intervention should be the treatment of choice for certain surgically remediable epileptic syndromes.
\end{abstract}

NEUROLOGY 2003;60:538-547

Epilepsy is a chronic neurologic disorder that affects 0.5 to $1 \%$ of the world's population. ${ }^{1}$ In the United States and other industrialized countries, where many antiepileptic drugs are readily available, 30 to $40 \%$ of patients continue to have seizures that are not adequately controlled by pharmacotherapy. ${ }^{2}$ Ac-

Additional material related to this article can be found on the Neurology Web site. Go to www.neurology.org and scroll down the Table of Contents for the February 25 issue to find the link for this article. cording to the World Health Organization, disability due to epilepsy accounts for approximately $1 \%$ of the global burden of disease, as measured by disabilityadjusted life years (DALYs), which ranks epilepsy just after major affective disorders, dementias, and alcohol dependence among primary disorders of the nervous system, and comparable to the worldwide burden due to breast and lung cancer. ${ }^{3}$ Most of the health care costs of epilepsy are due to those patients with medically intractable seizures. ${ }^{4}$ Many of those

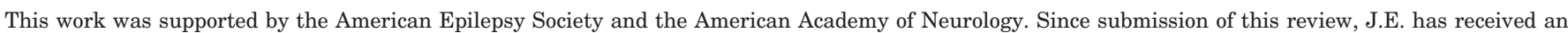

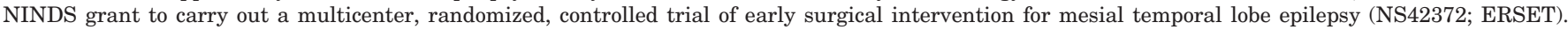
S.W., J.F., M.S., D.S., and R.G. are also participating in this study.

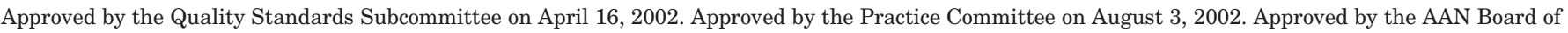
Directors on October 19, 2002.

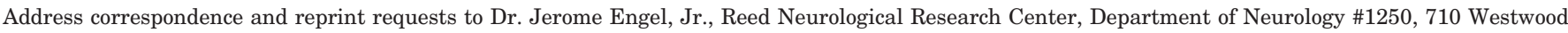
Plaza, Los Angeles, CA 90095-1769; e-mail: engel@ucla.edu 
disabled by epilepsy may be candidates for surgical therapy.

Surgical treatment for certain types of medically refractory epilepsy has been an option for more than 100 years, and recent advances in diagnostic procedures, particularly neuroimaging, have greatly increased interest in surgical therapy in the past 2 decades. The number of surgical procedures performed in the United States increased from approximately 500 in 1985 to approximately 1500 in 1990, and perhaps has doubled again since then; however, this is still more than an order of magnitude below what might be required to address the current need, with an estimated 100,000 to 200,000 potential surgical candidates in this country. ${ }^{5}$ Surgical treatment to abolish seizures has been particularly recommended for certain "surgically remediable syndromes," ${ }_{5,6}$ including mesial temporal lobe epilepsy, which may be the most common form of human epilepsy and the most refractory to pharmacotherapy, ${ }^{7}$ and neocortical epilepsy caused by discrete, easily resectable lesions. Early surgical intervention, when successful, might also prevent or reverse disabling psychosocial consequences of uncontrolled seizures during critical periods of adolescence and young adulthood. ${ }^{8}$ However, appropriate candidates for these procedures continue to be referred to epilepsy surgery programs late in the course of their disorder or not at all.

Mission statement. The Quality Standards Subcommittee of the American Academy of Neurology (AAN) is charged with developing practice parameters for neurologists for diagnostic procedures, treatment modalities, and clinical disorders. The selection of topics for which practice parameters are used is based on prevalence, frequency of use, economic impact, membership involvement, controversy, urgency, external constraints, and resources required. This article addresses published evidence on the safety and efficacy of localized resective surgery, either temporal or neocortical, as treatment for uncontrolled complex partial seizures.

Background and justification. Surgical efficacy can be compared to historical controls using results obtained from randomized clinical trials of antiepileptic drugs. These trials are usually carried out on patients with the same seizure types and response to medications as those treated surgically. ${ }^{9}$ For all such drug trials, a $50 \%$ reduction in seizure frequency experienced by $50 \%$ of the study population is considered to be a good result; very few patients are rendered seizure free. A meta-analysis by Cramer et al. ${ }^{10}$ demonstrated similar seizure reduction in several recent trials of new antiepileptic drugs. Drugs evaluated included gabapentin, lamotrigine, tiagabine, topiramate, and vigabatrin. Patients had three to four complex partial seizures/month at baseline. When the new antiepileptic drugs were added to the patients' regimen, the greatest efficacy achieved was
$54 \%$ of patients attaining a $50 \%$ reduction in seizure frequency (vigabatrin $6000 \mathrm{mg} /$ day). Most drugs achieved far lower seizure reduction rates. Seizure freedom was not addressed in most studies because it was rarely seen. A more recent study of the three newest antiepileptic drugs, levetiracetam, oxcarbazepine, and zonisamide, as well as the vagus nerve stimulator, demonstrated similar seizure reductions. ${ }^{11}$ All of the evaluated studies were placebo controlled. At best, placebo caused 50\% reduction in seizure frequency in only $18 \%$ of patients and seizure freedom was very rare. Although these patients differed from surgical patients in that they did not necessarily have focal resectable lesions and may have had more frequent seizures, these data indicate that neither continued pharmacotherapy nor placebo is likely to produce even short periods of complete seizure remission in medically refractory patients.

Clinical question statement. The following questions are addressed in this parameter: 1 ) What is the effectiveness of anteromesial temporal lobe and localized neocortical resections as a treatment for disabling complex partial seizures with respect to seizure recurrence, quality of life, and activities of daily living? 2) What is the risk of complications from these surgical interventions, compared with the efficacy and risks of continued pharmacotherapy?

Methods. Panel selection. In 1996, the American Epilepsy Society, in collaboration with the Quality Standards Subcommittee of the AAN, appointed a panel to develop practice parameters for surgical treatment of epilepsy. The American Association of Neurological Surgeons subsequently agreed to join this project. The core working group consisted of four neurologists who were directors of epilepsy centers that offered surgical treatment (J.E., R.G., M.S., P.W.), a neurosurgeon who was director of an epilepsy surgery program (D.S.), and a neurologist with particular expertise in outcomes research (S.W.). Additional panelists included two members of the Quality Standards Subcommittee, one of whom was an epileptologist (J.F.) and another who was not (C.Z.); a neurologist who was director of an epilepsy program for a health maintenance organization (B.E.); and a general neurologist (E.W.).

Literature review process. The initial comprehensive literature search was performed by the University of Minnesota, using Medline and Current Contents to identify all relevant papers published between January 1, 1990 and June 1999. Two lists of search terms were used, and at least one term from each list needed to be present for a paper to be identified. The first list included the following terms: seizures, epilepsy, Lennox-Gastaut, West syndrome, infantile spasms, Landau-Kleffner, hypothalamic hamartoma, cortical dysplasia, hemimegencephaly, tuberous sclerosis, Sturge-Weber, Rasmussen's encephalitis, mesial temporal sclerosis, hippocampal sclerosis, and drop attacks. The second list included the following terms: surgery, amygdalohippocampectomy, multiple subpial transection, lobectomy, corticectomy, corpus callosotomy, corpus callosum transection, amygdalotomy, hemispherectomy, and resection. This search yielded 1282 citations. 
After reviewing the abstracts, 415 were considered to contain potentially usable information for this study and were reproduced in full.

Three panel meetings were held. At the first meeting in December 1997, it became apparent that only papers that reported series with pure anteromesial temporal lobe resections, pure localized neocortical resections, or both, were sufficiently numerous to analyze. For the purposes of this review, no distinction was made among the various types of anteromesial temporal resections performed, which ranged from selective amygdalohippocampectomy to large tailored anterior temporal lobe excisions. All patients included in this initial review underwent surgery for what was considered to be medically refractory complex partial seizures with or without secondarily generalized seizures.

At the second meeting in December 1998, inclusion criteria for published surgical series were further refined to make sure results would be as generalizable as possible to all temporal lobe and neocortical resections. For anteromesial temporal lobe resections, papers were excluded if the study population was limited to only a subset of a larger population of patients who ordinarily would be considered for this surgical procedure. For instance, papers were excluded when they included only patients with tumors on MRI, only patients with bilateral independent EEG spikes, only patients who had invasive recording, or only children or the elderly. Because exclusively pediatric studies were not included and data were not analyzed by age, this review has limited applicability to children. For localized neocortical resections, exclusion criteria were similar, except that series devoted entirely to frontal lobe or occipital lobe resections were permitted.

Two specific postoperative outcome measures were chosen: frequency of epileptic seizures other than auras ${ }^{12}$ (simple partial seizures without motor features) and quantitatively measured health-related quality of life (QOL). ${ }^{13}$ The majority of papers used a standardized seizure outcome classification system with minor variations, ${ }^{12}$ which identified patients who were free of disabling seizures (and therefore permitted persistent auras), improved, and not improved (accepting whatever standard the investigators used to differentiate these latter two groups). The evaluation periods varied and it was not possible to segregate outcome results according to all the various periods of follow-up reported. Data were also used from the few papers that did not use this standardized scale when it was at least possible to segregate patients who were free of disabling seizures from those who were not. Papers that included other outcome measures regarding psychiatric status, work, school, neurocognitive function, driver's licensing, and mortality were also reviewed. Finally, all papers included in the study were evaluated for data that would reveal the incidence and nature of surgical complications.

Papers were ranked according to class of evidence (table 1). In the initial review there were no Class I reports. One would have met criteria for Class $\mathrm{II}^{14}$ and the remainder for Class III, except that none had a masked outcome assessment; therefore, all were Class IV. Papers were further evaluated according to a rating scale (see the Appendix on the Neurology Web site; go to www.neurology.org) designed to eliminate papers with less reliable data, and to permit stratification of the remainder at a later date, if desired, according to criteria that might influence
Table 1 AAN evidence classification scheme for a therapeutic article

Class I: Prospective, randomized, controlled clinical trial with masked outcome assessment, in a representative population.

The following are required:

a) Primary outcome(s) is/are clearly defined.

b) Exclusion/inclusion criteria are clearly defined.

c) Adequate accounting for drop-outs and crossovers with numbers sufficiently low to have minimal potential for bias.

d) Relevant baseline characteristics are presented and substantially equivalent among treatments groups or there is appropriate statistical adjustment for differences.

Class II: Prospective matched group cohort study in a representative population with masked outcome assessment that meets a-d above OR a randomized, controlled trial in a representative population that lacks one criteria a-d.

Class III: All other controlled trials (including well-defined natural history controls or patients serving as own controls) in a representative population, where outcome assessment is independent of patient treatment.

Class IV: Evidence from uncontrolled studies, case series, case reports, or expert opinion.

the results of the evaluation. The content, validity, and relevance of the rating scale were addressed by scoring a large number of articles and by panel discussion. Based on this rating scale, series were excluded if they contained less than 20 patients, if the outcome assessment was unclear, if the surgical intervention was not adequately described, or if any patients in the series underwent surgery before 1974, when modern neuroimaging was not generally available. For all outcome assessments, series were excluded if follow-up for any patients was less than 1 year. Of particular interest for later stratification were series in which all patients underwent surgery after 1985, when MRI was widely available, and series in which all patients had at least 2 years of follow-up.

At the third meeting in August 1999, the rating scale was used to select those papers that would make up the data set from 171 papers that remained from the University of Minnesota search, and 2 others were added as a result of independent searches carried out by the panelists. In order to avoid including overlapping data reported more than once from the same center, when two or more papers from the same center met the inclusion criteria, only the largest or most recent study was used for each specific review objective. If several papers from the same center recorded results of patient populations that were overlapping, one paper might be used for one review objective, while a different paper might be chosen for another review objective.

A final literature search through September 2001 for new studies meeting Class I criteria yielded one randomized, controlled trial of surgery for temporal lobe epilepsy with a masked outcome assessment, published in August $2001 .^{15}$ Results of this study were essentially identical to those obtained from our earlier literature review.

Analysis of evidence. Seizure outcomes were analyzed for anteromesial temporal lobe resections and for localized neocortical resections separately. In addition, data were obtained for QOL outcome, other outcomes affecting activ- 
ities of daily living, and surgical complications. Data for seizure outcome were categorical. When possible, these data were pooled. Because each study reported more than one outcome, e.g., free of disabling seizures, improved, and not improved, weighted averages were obtained by weighing each proportion by the study sample size. ${ }^{16}$ The results of the Class I study are not included in the original data set. They are reported separately and in detail, first, as the primary evidence for establishing these guidelines.

Class I randomized, controlled trial. In the single Class I randomized, controlled trial of epilepsy surgery, ${ }^{15}$ 80 patients with suspected mesial temporal lobe epilepsy were randomly assigned to surgical or medical study groups before presurgical evaluation. Those assigned to the surgical group received temporal lobe surgery immediately if the presurgical evaluation revealed that they were surgical candidates. Those assigned to the medical group were placed on the usual 1-year waiting list for surgery, during which time they continued to receive antiepileptic drug treatment. At the end of 1 year, $58 \%$ of patients in the surgical group were free of disabling seizures, and 10 to $15 \%$ had little or no improvement compared to only $8 \%$ free of disabling seizures in the medical group $(p<0.001)$, as determined by an independent investigator (masked outcome). Thirty-eight percent of patients in the surgical group were free of all seizures, including auras, compared with $3 \%$ in the medical group. Because this was an intention-to-treat paradigm, 4 of the 40 patients randomized to surgery were not considered surgical candidates after presurgical evaluation and continued to be treated medically. Of the remaining 36 patients who did receive a surgical intervention, $64 \%$ were free of disabling seizures. Furthermore, this study demonstrated a significant improvement in quantitative QOL and a trend toward better social function at the end of 1 year for patients in the surgical group compared to the medical group. There was no surgical mortality, but one patient on the medical arm died. Morbidity was minimal and similar in both groups.

Initial literature review. Seizure outcome for anteromesial temporal lobe resections. Twenty-four papers from an equal number of epilepsy surgery centers met the criteria for this analysis. ${ }^{17-40}$ Three methodologic deficiencies were noted. First, all studies but one ${ }^{37}$ were retrospective. Second, quantitative information about preoperative seizures was rarely provided; authors typically described the patients as having frequent disabling complex partial seizures with or without generalization. Third, as noted previously, in no study was the seizure outcome assessment masked. The total number of patients in this sample was 1952 and 1285 (67\%) were reported to be free of disabling seizures. Of this total, 21 centers reported their results on 1769 patients in three categories ${ }^{17,19-28,30,37,39}$ : $1150(65 \%)$ were free of disabling seizures, $372(21 \%)$ were improved, and 247 (14\%) were not improved. Only one center reported postoperative auras as well as disabling seizures and found $45.9 \%$ of patients to be completely seizure free.

Weighted averages are shown in table 2 for all 24 centers, for the 21 with three outcome categories, stratified by geographical region (Europe, ${ }^{23,36,38,40}$ Asia, ${ }^{22,28,30}$ Australia ${ }^{19,26,33}$ ), by 2 to 5 years (as opposed to 1 year) of follow-up, ${ }^{18,19,23,25,28,30,32,36,37}$ and by centers that included no patients who underwent surgery before the general availability of MRI for presurgical evaluation. ${ }^{17}$ 19,22,24,26-29,31-35,37 The results demonstrate that surgical outcome was consistent, differing little among stratifications, and on average were identical to those of the Class I study. Approximately two-thirds of patients were free of disabling seizures, and those who were considered to be unimproved ranged from 11 to $15 \%$.

Seizure outcome for localized neocortical resections. Many papers were excluded from consideration because the studies only evaluated patients with specific neocortical lesions. Eight papers could be included in this analysis. ${ }^{22,36,41,46}$ Methodologic problems were similar to those described above for the analysis of anteromesial temporal lobe resections. The total number of patients in the sample was 298 . Of these, $148(50 \%)$ were reported to be free of disabling seizures. Six of the eight centers had data allowing separation of results into three categories: 118 (49\%) were free of disabling seizures, $72(30 \%)$ were improved, and $49(21 \%)$ were not improved. ${ }^{22,36,41,44-46}$

Weighted averages are shown in table 3. Despite the small numbers, the results were consistent. About half of the patients who had neocortical resections became free of disabling seizures. Better results might be expected if series of lesional cases only were included,,$^{5}$ an issue that needs to be examined separately. However, five of the eight centers did note outcomes separately for patients with and without lesions. ${ }^{22,42,44-46}$ Of 131 lesional cases, $63 \%$ were free of disabling seizures.

Quality of life outcome. Six studies analyzing 521 patients fulfilled the eligibility criteria (see the Appendix on

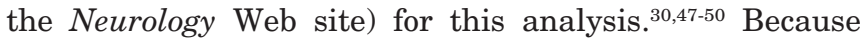
studies differed widely in their conceptualization of QOL, methods, QOL instruments, mode of reporting, and patient population, meaningful data pooling was not possible. For this overview, we adopted the authors' own definition of QOL, which encompasses constructs such as patient satisfaction, psychosocial function, and subjectively determined health-related QOL. Most of the data pertain to temporal lobe epilepsy and only two studies had nonsurgical, nonrandom controls. ${ }^{14,48}$ Except for the Class I study discussed above, ${ }^{15}$ other articles did not report on preoperative QOL measures or within-patient change over time. None of the articles reporting significant changes in QOL explored the clinical relevance of these changes.

Temporal lobe. Average satisfaction reported 1 year after anteromesial temporal resection on a 7-point Likert scale $(7=$ highest satisfaction $)$ in 100 patients and 91 significant others revealed that patients who are free of disabling seizures (Likert $=6.65$ ) and their significant others (Likert $=6.72$ ) are more satisfied than patients who are not free of disabling seizures and their significant others (Likert $=3.89$ and 4.5, respectively, $p<0.001$, for both) ${ }^{47}$ Similarly, in a study assessing psychosocial function in 79 patients using the Washington Psychosocial Seizure Inventory (WPSI), improvement in overall scores was larger in patients free of disabling seizures (7.8 vs $2.3, p<$ $0.01)^{47}$

In 94 surgically treated and 36 medically treated patients, after a median follow-up of 3 years postsurgery, results of the Liverpool QOL test battery (impact of epilepsy, affect, mastery, self-esteem, mood and overall QOL) were similar for patients with $>10$ disabling seizures/year and those who did not have surgery. Conversely, QOL was 
Table 2 Pooled seizure outcome following anteromesial temporal lobe resections are shown for all centers divided into two different outcome classifications

\section{4 centers reporting free of disabling seizures vs not free of disabling seizures}

Free $(95 \%$ CI)

1285

$66.8 \%(64-68)$
Not Free (95\% CI)

667

$34.2 \%(32-36)$

21 centers reporting free of disabling seizures, improved, not improved

Free $(95 \%$ CI)

1150

65\% (63-67)

\section{Improved $(95 \%$ CI)}

372

$21 \%(19-23)$
Not improved (95\% CI)

248

14\% (12-16)

Not improved $(95 \%$ CI)

78

$15.2 \%(13-18)$

Not improved (95\% CI)

24

$11.3 \%(8-15)$

Not improved $(95 \%$ CI)

31

$13.5 \%(9-18)$

$59.1 \%$ (53-65)

$27.4 \%(22-33)$

2-5 years follow-up

(9 centers)

Free $(95 \%$ CI)

Not free $(95 \%$ CI)

532

310

$63.2 \%(60-66)$

$36.8 \%$ (34-40)

(8 centers)

Free $(95 \%$ CI)

Improved $(95 \%$ CI)

Not improved (95\% CI)

480

185

102

$62.6 \%(59-66)$

$24.1 \%(21-27)$

$13.3 \%(11-16)$

All patients operated after 1985

(15 centers)

Free $(95 \%$ CI)

Not free $(95 \%$ CI)

713

333

$68.2 \%(65-71)$

$31.8 \%(29-35)$

(13 centers)

Free $(95 \%$ CI)

Improved (95\% CI)

Not improved (95\% CI)

617

183

117

$67.2 \%(64-70)$

$20 \%(17-22)$

Separate data are also shown for European, Asian, and Australian centers for comparison with the total database, which was predominantly from North American Centers, as well as for those series that followed patients for 2 to 5 years and series where all patients underwent surgery after 1985, when MRI became available. None of these data subsets differed significantly from the main data set. The total numbers of patients, percent, and 95\% CI are shown for each outcome category.

better in patients with $<10$ disabling seizures/year and best in those who were free of disabling seizures $(p<0.05){ }^{48}$

After a median follow-up of 5 years postsurgery in 132 patients and their families, a Japanese study using a questionnaire specifically designed for the study found overall QOL to be less than satisfactory in $14 \%$, satisfactory in $31 \%$, and completely satisfactory in $55 \%$. Most of the satis- faction was accounted for by QOL related to disabling seizures and $88 \%$ of patients described their overall QOL as improved or much improved. Conversely, 22 to $49 \%$ of patients reported either no improvement or worsening in specific areas such as leisure activities, emotional and physical well-being, financial status, and social relations. One-third each reported improvement, no change, or dete- 
8 Centers reporting free of disabling seizures vs. not seizure free of disabling seizures

Free $(95 \%$ CI)

148

$49.7 \%(44-55)$

6 centers reporting free of disabling seizures, improved, not improved

Free $(95 \%$ CI)

118

$49.4 \%(43-56)$
Not free $(95 \%$ CI)

150

$50.3 \%(45-56)$
Improved $(95 \%$ CI)

72

$30.1 \%(25-36)$
Not improved $(95 \%$ CI)

49

$20.5 \%(16-25)$ rioration in QOL as it related to memory function. Using this ad hoc QOL questionnaire, there was a weak positive correlation between earlier surgery and better QOL scores $(p<0.01){ }^{30,49}$

Temporal and extratemporal. In a retrospective study of 202 surgically treated and 46 medically treated patients, after a median follow up of 5.8 years there was a trend toward better scores on generic measures of activities of daily living and satisfaction (Katz adjustment scales), but the improvements were small and not significant. Conversely, seizure-targeted health perceptions, social function, pain, and role limitations caused by physical and emotional problems explored by the Epilepsy Surgery Inventory-55 (ESI-55) were better $(p=0.05)$ in patients who underwent surgery as opposed to patients who did not undergo surgery. ${ }^{14}$ Similarly, in a study of 224 adults, QOL as determined by the ESI-55 was best in patients free of disabling seizures and worst in those with continued disabling seizures $(p<0.05)$. Patients with auras had only intermediate QOL scores. ${ }^{50}$ None of the articles reporting statistically significant changes in QOL explored the clinical significance of these changes.

Ancillary outcomes. Seventeen studies met criteria for ancillary outcome analysis (see the Appendix on the Neurology Web site): two for psychiatric outcome, ${ }^{51,52}$ nine for neuropsychologic and psychosocial functions, ${ }^{37,47,52-58}$ five for employment status, ${ }^{14,32,59-61}$ one for activities of daily living, ${ }^{32}$ two for mortality, ${ }^{14,62}$ and one for medication. ${ }^{50}$

Psychiatric. Transient psychiatric disturbances lasting weeks to months, particularly dysphoria, were common after epilepsy surgery and most often occurred in the first year after surgery. These were seen in 25 to $40 \%$ of patients. $^{43,51}$ Worsening was seen both in patients with and without preoperative psychiatric diagnoses. De novo psychiatric disturbances occurred more often in those with persistent disabling seizures after surgery than in patients who became free of disabling seizures $(p<0.01){ }^{51}$

Neuropsychologic and psychosocial functioning. Psychosocial status after surgery depended largely on seizure outcome and preoperative psychosocial adjustment $(p<$ 0.01).52 The best adjustment occurred in individuals who were higher functioning before surgery and who became free of disabling seizures after surgery. Patients who became free of disabling seizures after anteromesial temporal lobe resection showed marked improvements in several domains. Improvements were noted in subscales of the Minnesota Multiphasic Personality Inventory (depression, psychasthenia), WPSI, Beck depression inventory, and trait anxiety scores compared with preoperative scores. ${ }^{37,47}$ Patients who continued to experience postoperative dis- abling seizures functioned at their preoperative level in the preceding scales.

Anteromesial temporal lobe resection had materialspecific effects on language and memory. Although test results showed no significant change in mean scores in large groups of patients after surgery, individuals displayed differences in cognitive function after surgery, improving in some areas and declining in others. Verbal and visuospatial memory function changed after temporal lobe surgery, depending on the side of surgery and level of preoperative cognitive functioning. ${ }^{37,53,56}$ Average or high preoperative memory performance was associated with a postoperative decline of $10 \%$ or more in some Wechsler Memory Scales (WMS) after dominant temporal lobe surgery. ${ }^{54}$ In contrast, patients with below-average preoperative memory were likely to improve in the WMS $(p<0.05)$. Verbal memory tended to improve after nondominant temporal lobe surgery and declined after dominant temporal lobe surgery $(p<0.05)$; visuospatial memory improved after dominant temporal lobe surgery and declined after nondominant temporal lobe surgery $(p<0.05)$. In a study of self-rating of memory, patients and their families on average rated memory as improved without laterality effects $(p<0.02) .{ }^{57}$

On average, naming did not change after dominant or nondominant temporal lobe surgery, although individual patients experienced improvement or impairment. ${ }^{54,56,58}$ In an extensive language battery, only the Token Test (which examines receptive comprehension) results differed between patients with dominant and nondominant temporal lobe surgery ${ }^{58}(p<0.05)$. Patients with dominant temporal lobe surgery showed a greater pre- to postoperative improvement in this measure than patients with nondominant surgery $(p<0.001)$.

Employment. Unemployment and underemployment rates are high preoperatively in patients who undergo epilepsy surgery. The major factors influencing postoperative employment were preoperative employment, seizure outcome, ability to drive, age at surgery, obtaining additional education after surgery, and postoperative neuropsychological functioning. ${ }^{32,59,60}$ Patients who were free of disabling seizures after surgery had higher employment levels than patients who continued to have disabling seizures $(p<0.001)$. In one series, 29 of 35 patients $(83 \%)$ who were free of disabling seizures since surgery worked full-time, whereas only 6 of 18 patients (33\%) with persistent disabling seizures in each year after surgery worked full-time; all patients free of disabling seizures were employed after surgery, while seven of 18 patients (39\%) with persistent disabling seizures were unemployed. ${ }^{60}$ However, 
there were conflicting results regarding the net effect of surgery on employment. ${ }^{14,32,59-61}$ A series in the United States $^{60}$ found that unemployment declined from 25 to $11 \%$ and another in Germany ${ }^{59}$ found a similar decline from 34 to $16 \%$, but not all individuals who were employed before surgery remained employed afterwards. A series of 23 patients from Japan reported that only 2 patients were employed full-time before surgery, while 10 were employed full-time after surgery. ${ }^{61}$ Two other series from the United States found no net effect on employment or unemployment rates. ${ }^{14,32}$ These disparities may reflect differences in patient selection and national economic fluctuations.

Activities of daily living and driving. After anteromesial temporal lobe resection, more patients operated a motor vehicle $(79 \%)$ than preoperatively $(20 \%)(p<$ $0.001){ }^{32}$ In addition, a higher proportion of patients were independent in activities of daily living after surgery $(88 \%)$ than before surgery $(68 \%)(p<0.001){ }^{32}$

Mortality. Mortality was related to seizure control after epilepsy surgery. One study of mortality in 393 patients who had epilepsy surgery found that patients who became free of disabling seizures after surgery had mortality rates indistinguishable from that of the general population, while patients with persistent disabling seizures had an elevated mortality rate (standardized mortality ratio of 4.69). ${ }^{37}$ In another study, 13 of 16 patients (81\%) who died during the follow-up period had experienced 2 or more disabling seizures in the preceding year. Only $47 \%$ of patients who survived had 2 or more disabling seizures in the latest year of follow-up. ${ }^{14}$

Medication. Patients who had epilepsy surgery of any type reduced the number of different antiepileptic drugs they took more than those who did not have surgery $(p<$ $0.001) .{ }^{14}$

Surgical complications. Seven institutions reported a total of 556 patients in whom the morbidity and mortality of resective procedures were sufficiently addressed. ${ }^{24,26,28,31,35,37,40}$ For all of these patients, there was an explicit discussion of whether an adverse outcome was resolved or permanent. The operations were predominantly of the temporal lobe; however, they included all lobes and both lesional and nonlesional cases.

Deaths. There were 2 deaths $(0.4 \%)$ that were nonoperative but occurred within 1 month of surgery. One was related to trauma and the cause of the other was not discussed. Two subdural hematomas were reported but did not lead to permanent injury.

New neurologic deficits. New neurologic deficits were reported in 34 patients (6\%). These were divided into 17 mild aphasias, 5 III or IV nerve palsies, 10 visual field deficits greater than a quadrant (deficits less than a quadrant are expected from anteromesial temporal lobe resections, detectable only by formal visual field testing, and not considered to be a complication), and 12 instances of hemiparesis. Sixteen $(3 \%)$ of these 34 patients had deficits that were transient, resolving within 3 months, and 18 $(3 \%)$ had deficits that were permanent. The majority of language problems involved comprehension and were seen after anteromesial temporal lobe resections. The hemipareses were primarily related to lesional resections adjacent to or within the primary motor cortex.

Postoperative infections. Twenty-six (5\%) postoperative infections were encountered: 9 wound, 2 meningitis, and 1 brain abscess. The remaining 14 were not classified and were from 1 institution. Deep vein thrombosis was described in only one patient but it is not clear that the other papers were including this as a complication to be reported. Hydrocephalus was seen in three instances of large resections.

Cognitive and behavioral changes. Only 3 papers $^{24,26,36}$ accounting for 219 patients briefly but formally discussed postoperative cognitive and behavioral changes in 12 patients $(6 \%)$. These consisted of four patients with memory problems after dominant temporal lobe surgery and eight patients with behavioral complaints, which were primarily depression. At least half of these resolved within 2 months. Most of these papers did not report formal quantitative neuropsychological or psychiatric testing pre- and postoperatively.

\section{Conclusions}

- Approximately two-thirds of patients become free of seizures, excepting simple partial seizures, after anterior temporal lobectomy. This outcome was found in a large number of Class IV series, and was confirmed in a randomized, controlled trial of surgery vs antiepileptic drug therapy. Ten to $15 \%$ are unimproved after surgery.

- In Class IV series, these findings change little when data are examined with respect to geographic region, longer follow-up, and surgery after the advent of MRI.

- Also in Class IV series, half of patients who undergo localized neocortical resections become free of disabling seizures and $15 \%$ are unimproved. Although the data set for localized neocortical resections is too small to stratify in the same manner as was done for anteromesial temporal lobe resections, these results are consistent across centers. No randomized trial has confirmed these findings.

- Quality of life scores improve after temporal lobectomy, but clinical significance of these measures was not studied. In the Class I trial, patients in the surgical group had better QOL scores than those in the medical group after 1 year. ${ }^{15}$ Other Class IV series demonstrated a positive correlation between degree of seizure improvement and QOL scores, and at least some aspects of QOL scores were better in patients who underwent surgery than in those who did not undergo surgery. As early as 1 year after surgery, patients who are free of disabling seizures have significantly better QOL scores than those who are not seizure free.

- There is a trend toward better social function among patients who received surgery in the Class I trial ${ }^{15}$ and in several Class IV series. Psychiatric outcome and neuropsychologic and psychosocial function after surgery can improve or worsen, with worsening related predominantly to persistence of seizures. Employment status and activities of daily living in general improve, mortality is decreased, and medication regimens are reduced after surgery. 
- Surgical morbidity and mortality are small. No surgical mortality and low morbidity were reported in the Class I randomized, controlled trial. ${ }^{15}$ Surgical complications were reported in $11 \%$ of 556 patients from 7 centers; 3\% experienced permanent neurologic deficits. Two patients $(0.4 \%)$ in this group died within a month after surgery, but deaths were unrelated to the surgical procedure. Postoperative cognitive and behavioral disturbances were described in 3 papers, occurred in $6 \%$ of patients, and were permanent in $3 \%$.

- The greater potential for achieving freedom from disabling seizures offered by surgical treatment, as opposed to continuing pharmacotherapy, may reduce the risks of long-term mortality. As compared to the surgical risks described above, mortality in randomized clinical trials of antiepileptic drugs may be as high as $0.78 \%$ per year. ${ }^{62}$ Furthermore, other studies have reported that successful surgical intervention can reduce this risk of mortality from continuing epileptic seizures manyfold. ${ }^{14,63}$

- The results of the Class I randomized, controlled study ${ }^{15}$ are augmented by data from the literature review. The evidence provided by the literature review supports the safety and effectiveness of anteromesial temporal lobe resection as a treatment for epilepsy. In appropriately selected patients ${ }^{64}$ this procedure offers a much greater potential to eliminate disabling seizures than continued pharmacotherapy, without adding an unacceptable risk compared to drug treatment.

- Although the methodologies and outcomes reported in these papers on anteromesial temporal lobectomies are similar to those concerned with localized neocortical resections, there remains no Class I or II evidence regarding the safety and efficacy of the latter surgical procedures.

- This evaluation does not address the efficacy of surgical intervention for specific types of epilepsy or underlying pathologic substrates. Nor does it evaluate the localizing or prognostic value of presurgical diagnostic tests or strategies. There were insufficient data in the literature to permit definitive evidence-based conclusions regarding the safety and efficacy of a number of other surgical interventions that are now commonly practiced, including multilobar resections, hemispherectomies, corpus callosotomies, lesionectomies, and multiple subpial transections. Furthermore, the data presented here do not permit conclusions to be made about when surgery should be considered.

\section{Recommendations}

1. Patients with disabling complex partial seizures, with or without secondarily generalized seizures, who have failed appropriate trials of first-line antiepileptic drugs should be considered for referral
Table 4 AAN system for translation of evidence to recommendations

Translation of evidence to

recommendations

Rating of recommendations

Level A rating requires at

least one convincing

class I study or at least

two consistent,

convincing class II

studies

Level B rating requires at least one convincing class II study or overwhelming class III evidence

Level C rating requires at least two convincing class III studies

$\mathrm{A}=$ Established as useful/ predictive or not useful/ predictive for the given condition in the specified population

B = Probably useful/ predictive or not useful/ predictive for the given condition in the specified population

$\mathrm{C}=$ Possibly useful/ predictive or not useful/ predictive for the given condition in the specified population

$\mathrm{U}=$ Data inadequate or conflicting. Given current knowledge, test, predictor is unproven

to an epilepsy surgery center, ${ }^{65}$ although criteria for failure of drug treatment have not been definitely established. (A) (table 4).

2. Patients referred to an epilepsy surgery center for the reasons stated above who meet established criteria for an anteromesial temporal lobe resection and who accept the risks and benefits of this procedure, as opposed to continuing pharmacotherapy, should be offered surgical treatment. ${ }^{66,67}$ (A)

3. There is insufficient evidence at this time to make a definitive recommendation as to whether patients with a localized neocortical epileptogenic region will benefit or not benefit from surgical resection. (U)

Future research. The relatively modest improvements in QOL and ancillary outcomes reported here may reflect the fact that most patients in the Class I trial and the Class IV series were adults who had had disabling seizures for several decades, resulting in relatively irreversible psychosocial consequences. Early surgical intervention might yield better outcomes. The concept of medical intractability cannot be taken literally, now that the number of available antiepileptic drugs is so great that it would take a lifetime to try each one individually, and in every possible combination, in any given patient. If surgical intervention is to be practical, it must be offered before pharmacoresistance is unequivocally proven in most patients. This practice parameter provides no evidence for guidelines on when to abandon pharmacotherapy and consider surgical intervention. ${ }^{8,68,69}$ The literature suggests that the prognosis for complete freedom from disabling seizures following failure of two antiepileptic drugs diminishes rapidly as 
more antiepileptic drugs are found to be ineffective, that very few patients become free of disabling seizures when it is considered necessary to use two antiepileptic drugs, and that virtually none become free of disabling seizures when three drugs are necessary. ${ }^{2}$ Contrasting these data with the consistently excellent prognosis for becoming free of disabling seizures with surgical intervention and the increasing evidence that continuation of disabling seizures over many years, particularly through adolescence and young adulthood, can result in irreversible psychosocial consequences raises consideration of surgical intervention for complex partial seizures after failure of two or three first-line antiepileptic drugs. Multicenter, randomized, controlled trials of early surgical intervention for specific surgically remediable syndromes, such as mesial temporal lobe epilepsy, are needed to determine when in the course of the epileptic disorder this alternative therapy should be offered.

Because most epilepsy surgery centers perform relatively few multilobar resections, hemispherectomies, corpus callosotomies, lesionectomies, and multiple subpial transections compared to anteromesial temporal lobe and localized neocortical resections, and reported series usually contain fewer than 20 patients, multicenter, prospective studies should be undertaken for independent evaluation of the safety and efficacy of these increasingly important surgical interventions. Sufficient data may already exist to permit a useful retrospective analysis if enough centers were involved.

Determination of the localizing and prognostic values of specific presurgical diagnostic tests and presurgical evaluation strategies based on the current published literature would be difficult to impossible because of the tremendous variation from center to center in the way these tests are performed and the manner in which data are reported. Multicenter, prospective studies should be undertaken for this purpose.

There appears to be general consensus among epilepsy surgery centers regarding what are now considered to be surgically remediable syndromes ${ }^{5}$; however, within these groups surgical prognosis may be different, depending on the age of the patient and the underlying pathologic substrates. Studies are needed to determine variability of surgical outcomes related to hippocampal sclerosis and specific discrete focal lesions, including localized developmental abnormalities such as focal cortical dysplasias, particularly in children.

In the current climate of limited health care resources, cost-effectiveness of surgical treatment, as opposed to pharmacotherapy, must also be considered. Although economic savings to society might seem obvious if early surgical intervention renders two-thirds of patients, who would otherwise remain disabled, sufficiently free of disabling seizures to live an independent life, clear demonstration of costeffectiveness of surgery for epilepsy, particularly over the short-term, is still needed. Studies including an economic decision-tree analysis should be performed to permit more accurate comparisons between short-term costs associated with surgical intervention and those of pharmacotherapy in an equivalent patient population. Studies should also be designed to find more cost-effective approaches to surgical therapy that would not compromise efficacy or safety in order to ensure that existing health care resources will be readily available for this important alternative treatment modality.

Disclaimer. This statement is provided as an educational service of the American Academy of Neurology, the American Epilepsy Society, and the American Association of Neurological Surgeons. It is based on an assessment of current scientific and clinical information. It is not intended to include all possible proper methods of care for a particular neurologic problem or all legitimate criteria for choosing to use a specific procedure. Neither is intended to exclude any reasonable alternative methodologies. The AAN, AES, and AANS recognize that specific patient care decisions are the prerogative of the patient and the physician caring for the patient, based on all of the circumstances involved.

\section{Appendix}

Quality Standards Subcommittee Members: Gary Franklin, MD, MPH (Co-Chair); Catherine Zahn, MD (Co-Chair); Milton Alter, MD, PhD; Stephen Ashwal, MD; Richard M. Dubinsky, MD; Jacqueline French, MD; Michael Glantz, MD; Gary Gronseth, MD; Deborah Hirtz, MD; Robert G. Miller, MD; James Stevens, MD; and William J. Weiner, MD.

\section{References}

1. Hauser WA, Hesdorffer DC. Epilepsy: frequency, causes and consequences. New York: Demos Press, 1990.

2. Kwan P, Brodie MJ. Early identification of refractory epilepsy. N Engl J Med 2000;342:314-319.

3. Murray CJL, Lopez AD, eds. Global comparative assessment in the health sector; disease burden, expenditures, and intervention packages. Geneva: World Health Organization, 1994.

4. Begley CE, Annegers JF, Lairson DR, Reynolds TF, Hauser WA. Cost of epilepsy in the United States: a model based on incidence and prognosis. Epilepsia 1994;35:1230-1243.

5. Engel J Jr. Current concepts: surgery for seizures. N Engl J Med 1996; 334:647-652.

6. Langfitt JT. Cost-effectiveness of anterotemporal lobectomy in medically intractable complex partial epilepsy. Epilepsia 1997;38:154-163.

7. Engel J Jr. Etiology as a risk factor for medically refractory epilepsy: a case for early surgical intervention. Neurology 1998;51:1243-1244.

8. Davidson S, Falconer MA. Outcome of surgery in 40 children with temporal-lobe epilepsy. Lancet 1975;1:1260-1263.

9. French JA, Dichter MA, Leppik IE, eds. New antiepileptic drug development: preclinical and clinical aspects. Epilepsy Research (suppl 10). Amsterdam: Elsevier 1993:175-178

10. Cramer JA, Fisher R, Ben-Menachem E, French J, Mattson RH. New antiepileptic drugs: comparison of key clinical trials. Epilepsia 1999;40: $590-600$

11. Cramer JA, Ben-Menachem E, French J. Review of treatment options for refractory epilepsy: new medications and vagal nerve stimulation. Epilepsy Res 2001;47:17-25.

12. Engel J Jr, Van Ness P, Rasmussen TB, Ojemann LM. Outcome with respect to epileptic seizures. In: Engel J Jr, ed. Surgical treatment of the epilepsies. 2nd ed. New York: Raven Press, 1993:609-621.

13. Devinsky O, Cramer JA, eds. Assessing quality of life in epilepsy: development of a new inventory. Epilepsia 1993;34(suppl 4).

14. Vickrey BG, Hays RD, Rausch R, et al. Outcomes in 248 patients who had diagnostic evaluations for epilepsy surgery. Lancet 1995;346:14451449 . 
15. Wiebe S, Blume WT, Girvin JP, Eliasziw M. A randomized, controlled trial of surgery for temporal lobe epilepsy. N Engl J Med 2001;345:311318.

16. Greenland S. Quantitative methods in the review of epidemiologic literature. Epidemiol Rev 1987;9:1-30.

17. Arruda F, Cendes F, Andermann F, et al. Mesial atrophy and outcome after amygdalohippocampectomy or temporal lobe removal. Ann Neurol 1996;40:446-450.

18. Assaf BA, Ebersole JS. Visual and quantitative ictal EEG predictors of outcome after temporal lobectomy. Epilepsia 1999;40:52-61.

19. Berkovic SF, McIntosh AM, Kalnins RM, et al. Preoperative MRI predicts outcome of temporal lobectomy: an actuarial analysis. Neurology 1995;45:1358-1363.

20. Blume WT, Girvin JP. Altered seizure patterns after temporal lobectomy. Epilepsia 1997;38:1183-1187.

21. Chung MY, Walczak TS, Lewis DV, Dawson DV, Radtke R. Temporal lobectomy and independent bitemporal interictal activity: what degree of lateralization is sufficient? Epilepsia 1991;32:195-201.

22. Chung SS, Lee KH, Chang JW, Park YG. Surgical management of intractable epilepsy. Stereotact Funct Neurosurg 1998;70:81-88.

23. Elwes RDC, Dunn G, Binnie CD, Polkey CE. Outcome following resective surgery for temporal lobe epilepsy: a prospective follow up study of 102 consecutive cases. J Neurol Neurosurg Psychiatry 1991;54:949952 .

24. Holloway KL, Corrie WS, Wingkun EC, Johnson MH, Kuta AJ. Epilepsy surgery: removing the thorn from the lion's paw. South Med J 1995;88:619-625.

25. Holmes MD, Dodrill CB, Ojemann LM, Ojemann GA. Five-year outcome after epilepsy surgery in nonmonitored and monitored surgical candidates. Epilepsia 1996;37:748-752.

26. Kilpatrick C, Cook M, Kaye A, Murphy M, Matkovic Z. Non-invasive investigations successfully select patients for temporal lobe surgery. J Neurol Neurosurg Psychiatry 1997;63:327-333.

27. Lancman ME, Benbadis S, Geller E, Morris HH. Sensitivity and specificity of asymmetric recall on WADA test to predict outcome after temporal lobectomy. Neurology 1998;50:455-459.

28. Liu Z, Tian Z, Kang G, et al. Surgical therapy of temporal lobe seizures. Stereotact Funct Neurosurg 1992;58:194-199.

29. Loring DW, Meador KJ, Lee GP, et al. Wada memory performance predicts seizure outcome following anterior temporal lobectomy. Neurology 1994;44:2322-2324.

30. Mihara T, Inoue Y, Matsuda K, et al. Recommendation of early surgery from the viewpoint of daily quality of life. Epilepsia 1996;37(suppl 3): 33-36.

31. Olejniczak PW, Carey MC, Fisch BJ, Troupin AS, Tardo C, Hauck M. The Louisiana State University Comprehensive Epilepsy Program: procedures and outcomes. J La State Med Soc 1996;148:525-532.

32. Reeves AL, So EL, Evans RW, et al. Factors associated with work outcome after anterior temporal lobectomy for intractable epilepsy. Epilepsia 1997;38:689-695.

33. Roubina S, Mackenzie RA, Haindl W, Rossleigh M, Klamus J, Ellis M Can the interictal EEG predict successful temporal lobectomy for epilepsy? J Clin Neurosci 1997;4:47-50.

34. Salanova V, Markand O, Worth R, et al. FDG-PET and MRI in temporal lobe epilepsy: relationship to febrile seizures, hippocampal sclerosis and outcome. Acta Neurol Scand 1998;97:146-153.

35. Schuh LA, Henry TR, Fromes G, Blaivas M, Ross DA, Drury I. Influence of head trauma on outcome following anterior temporal lobectomy. Arch Neurol 1998;55:1325-1328.

36. Silander HC: son, Blom S, Malmgren K, Rosén I, Uvebrant P. Surgical treatment for epilepsy: a retrospective Swedish multicenter study. Acta Neurol Scand 1997;95:321-330.

37. Sperling MR, O'Connor MJ, Saykin AJ, Plummer C. Temporal lobectomy for refractory epilepsy. JAMA 1996;276:470-475.

38. Theodore WH, Sato S, Kufta C, Balish MB, Bromfield EB, Leiderman DB. Temporal lobectomy for uncontrolled seizures: the role of positron emission tomography. Ann Neurol 1992;32:789-794.

39. Wieser HG. Selective amygdalohippocampectomy: indications and follow-up. Can J Neurol Sci 1991;18:617-627.

40. Zentner J, Hufnagel A, Wolf HK, et al. Surgical treatment of temporal lobe epilepsy: clinical, radiological, and histopathological findings in 178 patients. J Neurol Neurosurg Psychiatry 1995;58:666-673.

41. Aykut-Bingol C, Bronen RA, Kim JH, Spencer DD, Spencer SS. Surgical outcome in occipital lobe epilepsy: implications for pathophysiology. Ann Neurol 1998;44:60-69.

42. Berg AT, Walczak T, Hirsch LJ. Spencer SS. Multivariable prediction of seizure outcome one year after resective epilepsy surgery: development of a model with independent validation. Epilepsy Res 1998;29:185-194.
43. Rougier A, Dartigues JF, Commenges D, Claverie B, Loiseau P, Cohadon F. A longitudinal assessment of seizure outcome and overall benefit from 100 cortectomies for epilepsy. J Neurol Neurosurg Psychiatry 1992;55:762-767.

44. Smith JR, Lee MR, King DW, et al. Results of lesional vs. nonlesional frontal lobe epilepsy surgery. Stereotact Funct Neurosurg 1997;69:202209 .

45. Swartz BE, Delgado-Escueta AV, Walsh GO, et al. Surgical outcomes in pure frontal lobe epilepsy and foci that mimic them. Epilepsy Res 1998; 29:97-108.

46. Zentner J, Hufnagel A, Ostertun B, et al. Surgical treatment of extratemporal epilepsy: clinical, radiologic, and histopathologic findings in 60 patients. Epilepsia 1996;37:1072-1080.

47. Wheelock I, Peterson C, Buchtel HA. Presurgery expectations, postsurgery satisfaction, and psychosocial adjustment after epilepsy surgery. Epilepsia 1998;39:487-494.

48. Kellett MW, Smith DF, Baker GA, Chadwick DW. Quality of life after epilepsy surgery. J Neurol Neurosurg Psychiatry 1997;63:52-58.

49. Mihara T, Inoue Y, Watanabe Y, et al. Improvement of quality-of-life following resective surgery for temporal lobe epilepsy: results of patient and family assessments. Jpn J Psychiatr Neurol 1994;48:221-229.

50. Vickrey BG, Hays RD, Graber J, Rausch R, Engel J Jr, Brook RH. A health-related quality of life instrument for patients evaluated for epilepsy surgery. Med Care 1992;30:299-319.

51. Blumer D, Wakhlu S, Davies K, Hermann B. Psychiatric outcome of temporal lobectomy for epilepsy: incidence and treatment of psychiatric complications. Epilepsia 1998;39:478-486.

52. Hermann BP, Wyler AR, Somes G. Preoperative psychological adjustment and surgical outcome are determinants of psychosocial status after anterior temporal lobectomy. J Neurol Neurosurg Psychiatry 1992;55:491-496.

53. Brockway JP, Follmer RL, Burrows GS, Solsrud KA, Greenhoot JH Improved cognitive performance following ATL. Brain Cogn 1996;32: $128-130$.

54. Chelune GJ, Naugle RI, Lüders H, Awad IA. Prediction of cognitive change as a function of preoperative ability status among temporal lobectomy patients seen at 6-month follow-up. Neurology 1991;41:399_ 404 .

55. Martin RC, Sawrie SM, Roth DL, et al. Individual memory change after anterior temporal lobectomy: a base rate analysis using regressionbased outcome methodology. Epilepsia 1998;39:1075-1082.

56. Morris RG, Abrahams S, Polkey CE. Recognition memory for words and faces following unilateral temporal lobectomy. Br J Clin Psychology 1995;34:571-576

57. McGlone J, Wands K. Self-report of memory function in patients with temporal lobe epilepsy and temporal lobectomy. Cortex 1991;27:19-28.

58. Hermann BP, Wyler AR, Somes G. Language function following anterior temporal lobectomy. J Neurosurg 1991;74:560-566.

59. Lendt M, Helmstaedter C, Elger CE. Pre- and postoperative socioeconomic development of 151 patients with focal epilepsies. Epilepsia 1997;38:1330-1337.

60. Sperling MR, Saykin AJ, Roberts FD, French JA, O'Connor MJ. Occupational outcome after temporal lobectomy for refractory epilepsy. Neurology 1995;45:970-977.

61. Mihara T, Matsuda K, Tottori T, et al. Surgical treatment of epilepsy in the comprehensive care program: advantages and considerations. Jpn J Psychiatr Neurol 1990;44:275-281.

62. Leetsma JE, Annegers JF, Brodie MJ, et al. Sudden unexplained death in epilepsy: observations from a large clinical development program. Epilepsia 1997;38:47-55.

63. Sperling MR, Feldman H, Kinman J, Liporace JD, O'Connor MJ. Seizure control and mortality in epilepsy. Ann Neurol 1999;46:45-50.

64. Wieser HG, Engel J Jr, Williamson PD, Babb TL, Gloor P. Surgically remediable temporal lobe syndromes. In: Engel J Jr, ed. Surgical treatment of the epilepsies. 2nd ed. New York: Raven Press, 1993:49-63.

65. National Association of Epilepsy Centers. Guidelines for essential services, personnel, and facilities in specialized epilepsy centers in the United States. Epilepsia 2001;42:804-814.

66. Engel J Jr, ed. Surgical treatment of the epilepsies. 2nd ed. New York: Raven Press, 1993.

67. Lüders HO, Comair YG. Epilepsy surgery. 2nd ed. Philadelphia: Lippincott Williams \& Wilkins, 2000.

68. Engel J Jr. The timing of surgical intervention for mesial temporal lobe epilepsy: a plan for a randomized clinical trial. Arch Neurol 1999;56: 1338-1341.

69. Engel J Jr. Finally, a randomized controlled trial of epilepsy surgery. N Engl J Med 2001;345:365-367. 


\section{Neurology}

Practice parameter: Temporal lobe and localized neocortical resections for epilepsy:

Report of the Quality Standards Subcommittee of the American Academy of Neurology, in Association with the American Epilepsy Society and the American Association of Neurological Surgeons

J. Engel, Jr., S. Wiebe, J. French, et al.

Neurology 2003;60;538-547

DOI 10.1212/01.WNL.0000055086.35806.2D

This information is current as of February 25, 2003

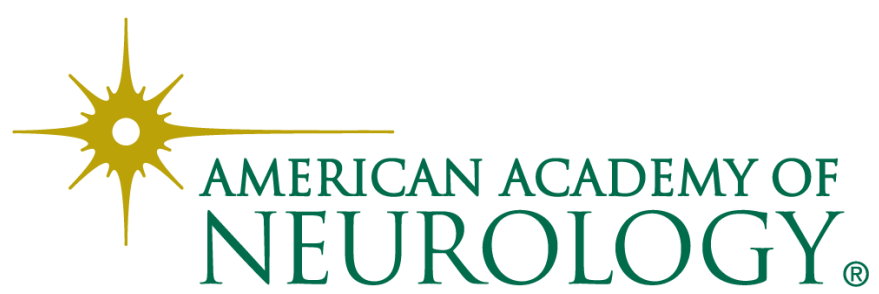




\section{Updated Information \& Services}

\section{Supplementary Material}

\section{References}

Citations

Subspecialty Collections

Errata

Permissions \& Licensing

Reprints including high resolution figures, can be found at:

http://n.neurology.org/content/60/4/538.full

Supplementary material can be found at: http://n.neurology.org/content/suppl/2003/02/06/60.4.538.DC1 http://n.neurology.org/content/suppl/2017/05/01/60.4.538.DC2

This article cites 60 articles, 12 of which you can access for free at: http://n.neurology.org/content/60/4/538.full\#ref-list-1

This article has been cited by 38 HighWire-hosted articles: http://n.neurology.org/content/60/4/538.full\#\#otherarticles

This article, along with others on similar topics, appears in the following collection(s):

All Epilepsy/Seizures

http://n.neurology.org/cgi/collection/all_epilepsy_seizures Epilepsy surgery

http://n.neurology.org/cgi/collection/epilepsy_surgery_

An erratum has been published regarding this article. Please see next page or: /content/60/8/1396.full.pdf

Information about reproducing this article in parts (figures,tables) or in its entirety can be found online at:

http://www.neurology.org/about/about_the_journal\#permissions

Information about ordering reprints can be found online:

http://n.neurology.org/subscribers/advertise

Neurology ${ }^{\circledR}$ is the official journal of the American Academy of Neurology. Published continuously since 1951, it is now a weekly with 48 issues per year. Copyright . All rights reserved. Print ISSN: 0028-3878. Online ISSN: 1526-632X.

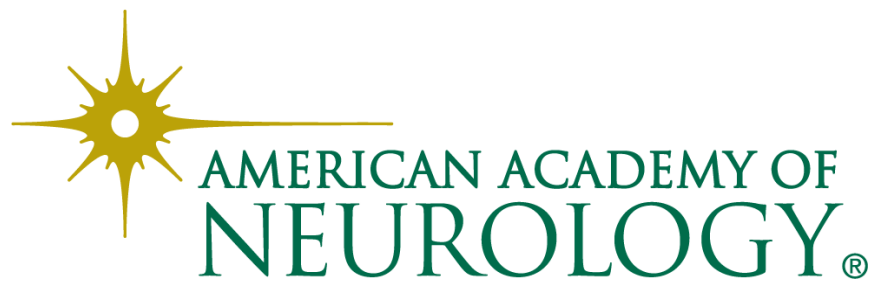




\section{Correction}

In the article "Practice Parameter: Temporal lobe and localized neocortical resections for epilepsy: Report of the Quality Standards Subcommittee of the American Academy of Neurology, in Association with the American Epilepsy Society and the American Association of Neurological Surgeons" (Neurology 2003;60:538-547), table 1 on p.540 was incorrect. The correct table is:

Table 1 AAN evidence classification scheme for a therapeutic article

Class I: Prospective, randomized, controlled clinical trial with masked outcome assessment, in a representative population.

The following are required:

a) Primary outcome(s) is/are clearly defined.

b) Exclusion/inclusion criteria are clearly defined.

c) Adequate accounting for drop-outs and crossovers with numbers sufficiently low to have minimal potential for bias.

d) Relevant baseline characteristics are presented and substantially equivalent among treatments groups or there is appropriate statistical adjustment for differences.

Class II: Prospective matched group cohort study in a representative population with masked outcome assessment that meets $\mathrm{a}-\mathrm{d}$ above $\mathrm{OR}$ a randomized, controlled trial in a representative population that lacks one criteria $\mathrm{a}-\mathrm{d}$.

Class III: All other controlled trials (including well-defined natural history controls or patients serving as own controls) in a representative population, where outcome assessment is independent of patient treatment.

Class IV: Evidence from uncontrolled studies, case series, case reports, or expert opinion. 